\title{
Malignant Tumors Arising De Novo in Immunosuppressed Organ Transplant Recipients ${ }^{1}$
}

\author{
Israel Penn and Thomas E. Starzl \\ Department of Surgery, University of Colorado School of Medicine, and the Veterans \\ Administration Hospital, Denver, Colorado 80220
}

\section{Summary}

De novo malignant tumors have been observed throughout the world in 75 chronic survivors of organ transplantation, including 16 of our own patients. The incidence of tumors was approximately 80 times greater than in the average population in a comparable age range. Chronic uremia may have predisposed to the development of some of the tumors, but this has not yet been proved. It seems clear that the predominant etiology was chronic immunosuppression posttransplantation. Forty-four of the patients had epithelial tumors and in 31 the lesions were of mesenchymal origin. On the average the malignancies appeared 29 months after transplantation. Lymphomas showed an unusual predilection for involvement of the central nervous system. Carcinomas of the skin, lip, and uterine cervix were successfully treated by conventional techniques. On the other hand, carcinomas of the thoracic or abdominal organs and mesenchymal tumors led or contributed to early death in most cases. For this reason drastic reduction or even discontinuance of immunosuppression should be considered in the management of these latter tumors.

In recent years a convincing association between immunosuppression and malignant neoplasms in organ transplant recipients has become evident. In some patients tumors have been accidentally transplanted from donors with cancer $(15,28,29)$, or there has been growth of residual or metastatic tumor in patients with preexisting malignancy $(15,28,29)$, or neoplasms have arisen de novo at some time after transplantation. This report will be restricted to the last group of tumors.

After we first described the development of de novo malignancies in renal homograft recipients in $1968(18,25,27)$, an informal tumor registry was established in Denver. Physicians from transplant centers throughout the world have generously contributed data concerning their patients. The present report deals with all cases recorded until December 31, 1971 and involves 75 patients with 76 types of tumors.

\section{Incidence}

Up to the fall of 1971, 7,581 renal and 179 cardiac homografts had been reported to the American Cancer Society-National Institutes of Health Organ Transplant Registry (2). However, it is well recognized that these figures are incomplete as are the numbers of tumors reported. In order to determine accurately the incidence of de novo malignancies, we have reviewed the renal transplantation experience at the University of Colorado Medical Center and the Denver Veterans Administration Hospital. The studies involved patients

\footnotetext{
${ }^{1}$ This work was supported by research grants from the Veterans Administration, by Grants RR-00051 and RR-00069 from the General Clinical Research Centers Program of the Division of Research Resources, National Institutes of Health, and by Grants AI-10176-01, AI-AM-08898, AM-07772, and HE-09110 from the United States Public Health Service.
} 
treated between November 1962 and July 1, 1971, who on December 31, 1971 had potential followups of from 6 months to more than 9 years. Sixteen of 352 patients had developed tumors (Tables 1 and 2), giving a crude incidence of $4.5 \%$. This figure does not reflect the true frequency of post-transplantation neoplasia, since 66 patients died of a variety of other complications before the end of the 4 th postoperative month. The 16 tumors occurred in the remaining 286 patients for a partially corrected incidence of $5.6 \%$. This correction, obtained by excluding from the denominator those patients who did not survive a minimum of 4 months after transplantation, may no longer be justified, since tumors have been diagnosed in several centers during this early period as will be described later.

The rate of tumor development in these generally young patients $\left(3 \frac{1}{2}-53\right.$ years old, average age approximately 28 years) compares with an annual incidence of 58/100,000 $(0.058 \%)$ in the general population in a comparable age range (7). The latter statistic excludes carcinomas in situ. In our transplant series 3 of the 16 malignancies were of this kind. Even if these 3 cases are omitted the incidence of malignancy in the 286 patients is $4.5 \%$, still a high figure.

\section{Tumor Types and Organs Affected}

Of the 76 tumors reported to date, 44 were of epithelial origin (Table 1). The most common of these were squamous or basal cell skin carcinomas (11 cases), in situ carcinomas of the cervix uteri (8 cases), carcinomas of the lip ( 8 cases), carcinomas of the lung ( 3 cases), hepatomas ( 2 cases), colonic carcinomas ( 2 cases), and highly anaplastic carcinomas of uncertain origin ( 2 cases). In addition, there was one example each of carcinoma of the ovary, testis, floor of the mouth, stomach, thyroid, and breast. In a further case the origin of a widespread squamous cell neoplasm was never established. There was also a case of a primary carcinoma involving the transplanted kidney (case 42, Table 1), but there is some question as to whether this was truly a de novo neoplasm or whether a small undetected tumor may have been present in the organ at the time it was harvested from a cadaver donor.

Thirty-two mesenchymal tumors were encountered in 31 patients (Table 2). These neoplasms were a much more homogenous group in that 28 were varieties of lymphoma including 21 examples of reticulum cell sarcoma. One of the latter patients also had a Kaposi's sarcoma. This type of lesion was found in two further patients, while unclassified lymphomas were found in 3 , and a lymphosarcoma was found in 1 . Of the nonlymphomatous tumors, 2 were leiomyosarcomas, 1 was a synovial sarcoma, and 1 was a rhabdomyosarcoma.

An unusual feature of the lymphomas was the frequency with which the central nervous system was involved $(21,22)$. Of the 27 patients with lymphoma there were 14 with involvement of either the brain or spinal cord including 10 of the patients with reticulum cell sarcoma, 3 with unclassified lymphoma, and 1 patient with lymphosarcoma. Lymphoreticular tumors within the central nervous system are uncommon (0.04 and $1.5 \%$ in two large series) $(19,20)$; yet, in 11 instances in the present study, the brain or spinal cord were the only regions so affected. Probable explanations for the high incidence of central nervous system involvement have been discussed elsewhere $(17,21,22)$.

\section{Behavior of Tumors}

The mesenchymal tumors occurred in a slightly younger average age group than the epithelial lesions, 31 years compared with 35 years. The average time of appearance of the tumors after transplantation was 29 months. The mesenchymal neoplasms occurred at an average of 21 months after operation compared with the longer interval of 35 months with the carcinomas. 
A number of the epithelial tumors were of low grade malignancy and were treated successfully by conventional techniques (Table 1). Of the 44 patients in this group, 26 are currently alive including most of the patients with carcinomas of the skin, cervix uteri, and lip. The deaths of 3 patients with these latter lesions were unrelated to cancer. In contrast, the epithelial malignancies within the thorax and abdomen were the primary cause of death or contributed significantly to the fatal outcome. The recipients with mesenchymal tumors had a similar gloomy prognosis in that only 3 of the 31 patients are currently alive.

\section{Borderline Lesions}

An interesting feature of the present report is that in 6 of the 75 cases, the lesions were diagnosed in less than 4 months after transplantation (Tables 1 and 2). These included one case each of carcinoma of the skin, testis, colon, and thyroid gland, a lymphosarcoma of the brain, and a lymphoma of the spinal cord. One reasonable explanation could be that at least some of these tumors or even some of those with a later appearance were already present at the time of transplantation, but were small and undetected, and grew rapidly under the influence of the immunosuppressive therapy. This raises the question whether chronic renal failure per se may predispose the patient to malignant disease (15) by virtue of the well known depression in uremia of immune responses $(6,10,13,32)$.

Observations reported to the National Dialysis Registry (5) are neither for nor against this hypothesis. Among 4,600 patients on chronic dialysis programs, $1 \%$ were reported to have died from malignancies. However, these statistics were incomplete, as the cause of death in $7 \%$ of the patients was not known; besides, the patients' ages were not stated so it is not possible to compare cancer death rates in this group with those in the general population. Furthermore, the Dialysis Registry does not provide figures giving the incidence of tumors among living dialysis patients.

Among our own 352 renal recipients, there have been 3 patients who were proved to have malignant growths prior to transplantation. The lesions were of the bladder, the thyroid, and the skin. The thyroid carcinoma was an incidental finding at autopsy following sudden death 2 days after transplantation, but the bladder and skin cancers required surgical management both before and after transplantation. These latter tumors are now under control with posttransplantation followups of 1 and $2 \frac{1}{2}$ years.

A similar case to our thyroid carcinoma was in a patient of Dr. R. Simmons (personal communication) who underwent a parathyroidectomy 2 weeks after renal transplantation and was found to have an unsuspected papillary carcinoma of the thyroid gland. A patient on chronic hemodialysis at our medical center (A. Alfrey, personal communication) was also found to have a carcinoma of the thyroid gland during parathyroidectomy. Other malignancies encountered in patients with chronic uremia include a carcinoma of the parathyroid gland discovered during thymectomy performed 2 months before renal transplantation (S. Nakamoto, personal communication), a rhabdomyosarcoma of the shoulder in a patient on hemodialysis who was awaiting a cadaver kidney transplant ( $\mathrm{P}$. Inanovitch, personal communication), and a carcinoma of the ureter in a patient with chronic renal failure caused by analgesic nephropathy (M. Robertson, personal communication).

If uremia predisposed to malignancy by loss of immunological surveillance, it would not be surprising if carcinomas were found in the diseased native kidneys that are often excised before or at the time of transplantation. In our own case material, there have been no such examples. However, 12 cases of renal neoplasia have now been collected in patients with chronic renal failure. The features of these interesting cases are listed in Table 3. 


\section{Etiology of Tumors}

Apart from the possibility of preexisting neoplasia in the recipients, it is necessary to consider whether tumors were inadvertently transplanted from the donors. The 75 recipients received their transplants from 85 donors, 41 living volunteers, and 44 cadavers. None of the living donors has manifested evidence of malignant disease during followup periods as long as 9 years. Two cadaver donors (cases 4 and 28, Table 2) had medulloblastomas, whereas the recipients subsequently developed a gluteal reticulum cell sarcoma and a gastric leiomyosarcoma, respectively. The tumors in donor and recipient were morphologically distinct and there was probably no etiological connection unless they were both caused by an oncogenic virus that was transmitted with the donor kidney. A further cadaver donor (case 9, Table 2) had had a carcinoma of the colon resected 5 years previously but was apparently free of tumor at the time of transplantation. The recipient developed a reticulum cell sarcoma.

In experimental animals $(15,26,28)$, each of the main immunosuppressive agents, azathioprine, prednisone, and antilymphocyte globulin (ALG), has been shown either to: (1) increase the incidence of spontaneous, virus-induced, or chemically initiated tumors; (2) facilitate the ease with which malignant cells can be transplanted; or (3) accelerate metastatic growth. Thymectomy or splenectomy may also cause increased oncogenic susceptibility in experimental animals $(15,26,28)$.

In man there has so far been no evidence that any one of the individual immunosuppressive measures has made a unique contribution to the development of post-transplantation neoplasia. All the patients (Tables 1 and 2) received azathioprine and prednisone, 30 underwent splenectomy, 5 had thymectomy, and 2 had thoracic duct fistulas. It is of interest that 22 of 44 patients with epithelial tumors (50\%) underwent splenectomy, whereas 8 of 31 (26\%) with mesenchymal tumors were subjected to this procedure. Only 21 of the 75 patients were treated with ALG and 2 of these recipients received this therapy after the appearance of the tumor. In view of these findings it is difficult to understand the origin of the widespread misconception that the incidence of tumors in the post-transplantation period has increased since the introduction of ALG therapy.

The disproportionately high incidence of lymphomas may, in part, be an artefact in that there may be a tendency to report to the registry only the more florid and lethal malignancies and to dismiss many skin tumors or in situ carcinomas of the cervix as relatively unimportant. However, the disproportionate numbers of lymphomas may be real and may reflect the effects upon the host of the transplanted organ with its foreign histocompatibility antigens. Prolonged antigenic stimulation of the host reticuloendothelial system has been shown to cause a high incidence of lymphomas $(1,12,23,24,31)$.

While this may be the cause of at least some of the lymphomas, the most likely explanation for the wide spectrum of tumors observed in the present series is that chronic immunosuppression causes loss of the immunological surveillance mechanism by which tumor mutants are normally detected and destroyed $(3,4,30)$. This does not exclude other possible etiological factors such as a direct oncogenic effect of the immunosuppressive agents, potentiation of the effects of environmental carcinogens such as tobacco, ultraviolet light, or irradiation, or activation of oncogenic viruses. Concerning the last possibility, infection by viruses of the Herpes family have been very common in transplant recipients. Two human strains belonging to this group, the Epstein-Barr and Herpes hominis II viruses, have been found to be commonly associated with although not necessarily responsible for Burkitt's lymphoma and uterine cervical carcinoma, respectively. 


\section{Treatment of Tumors}

The epithelial malignancies of the skin, lip, and uterine cervix were successfully treated by standard surgical or radiotherapeutic techniques without risking the homografts by arbitrary reductions in immunosuppression. This approach has proved inadequate for dealing with most carcinomas involving the thoracic and abdominal organs and with most mesenchymal tumors. In view of the virtually hopeless prognosis it may be advisable to reduce drastically or even discontinue the immunosuppressive therapy. Three patients (cases 18, 21, and 23, Table 2) with mesenchymal tumors are currently alive following this form of treatment. One of the patients (case 23) is in excellent health more than $4 \frac{1}{2}$ years after transplantation and 4 years after the tumor was diagnosed. Two other patients (case 20, Table 2; case 37, Table 1), in whom immunosuppression was drastically reduced, died of septicemia and rejection, respectively, but at autopsy it was found that the previously widespread tumors had completely regressed.

If drastic reduction in immunosuppression fails to control the neoplasm, then some form of immunotherapy can be attempted $(9,11,14)$.

\section{Future Prospects}

The development of de novo malignant tumors in chronically immunosuppressed organ transplant recipients has added a new dimension to our understanding of the nature of cancer by emphasizing the role played by immune mechanisms in the control of neoplasia. Fortunately, the incidence of tumors is sufficiently low as not to contraindicate transplantation as a form of therapy. Much remains to be learned about the nature of the tumors. Electron microscope and culture studies are currently in progress to determine the role played by oncogenic viruses. Other investigations are aimed at determining whether patients with particular HL-A specificities may be more prone to the development of cancer as has been found in some forms of lymphoma (8) or whether certain HL-A mismatches between donor and recipient might lead to malignant change.

\section{References}

1. Armstrong MYK, Schwartz RS, Beldotti L. Transplantation 1967;6:1380.

2. Bergan JJ. ACS-NIH Organ Transplant Registry Fall Newsletter. 1971

3. Burnet FM. Brit Med J 1957;1:779, 841. [PubMed: 13404306]

4. Burnet FM. Progr Exp Tumor Res 1970;13:1. [PubMed: 4921480]

5. Burton BT, Krueger KK, Bryan FA Jr. J Amer Med Assoc 1971;218:718.

6. Dammin GJ, Couch NP, Murray JE. Ann N Y Acad Sci 1957;64:967. [PubMed: 13411933]

7. Doll, R.; Payne, P.; Waterhouse, J., editors. Cancer incidence in five continents A technical report (UICC). Springer-Verlag; New York: 1966.

8. Forbes JF, Morris PJ. Tissue Antigens 1971;1:265. [PubMed: 4949436]

9. Humphrey LJ. J Surg Res 1970;10:493. [PubMed: 4920329]

10. Kasakura S, Lowenstein L. Transplantation 1967;5:283.

11. Mathé G. Brit Med J 1969;4:7. [PubMed: 5258858]

12. Metcalf D. Acta Unio Int Contra Cancrum 1963;19:657. [PubMed: 14050630]

13. Morrison AB, Maness K, Tawes R. Arch Pathol 1963;75:139.

14. Morton DL, Holmes EC, Eilber FR, Wood WC. Ann Int Med 1971;74:587. [PubMed: 4927902]

15. Penn, I. Malignant tumors in organ transplant recipients. Springer-Verlag; New York: 1970.

16. Penn I, Starzl TE. Int J Clin Pharmacol 1970;1:106.

17. Penn I, Halgrimson CG, Starzl TE. Transpl Proc 1971;3:773.

18. Penn I, Hammond W, Brettschneider L, Starzl TE. Transpl Proc 1969;1:106. 
19. Richmond J, Sherman RS, Diamond HD, Craver LF. Amer J Med 1962;32:184. [PubMed: 14492019]

20. Rosenberg SA, Diamond HD, Jaslowitz B, Craver LF. Medicine 1961;40:31. [PubMed: 13743408]

21. Schneck SA, Penn I. Arch Neurol 1970;22:226. [PubMed: 4904201]

22. Schneck SA, Penn I. Lancet 1971;1:983. [PubMed: 4102451]

23. Schwartz R, Andre-Schwartz J. Ann Rev Med 1968;19:269. [PubMed: 4297618]

24. Schwartz R, Andre-Schwartz J, Armstrong MYK, Beldotti C. Ann N Y Acad Sci 1966;129:804.

25. Starzl TE. Ann Surg 1968;168:416. [PubMed: 4175449]

26. Starzl, TE. Experience, in hepatic transplantation. Saunders; Philadelphia: 1969. p. 350

27. Starzl TE, Groth CG, Brettschneider L, Smith GV, Penn I, Kashiwagi N. Antibiot Chemother 1969;15:349. [PubMed: 4180987]

28. Starzl TE, Penn I, Putnam CW, Groth CG, Halgrimson CG. Transpl Rev 1971;7:112.

29. Starzl, TE.; Putnam, CW.; Brettschneider, L.; Penn, I. Proceedings of the sixth national cancer conference; Philadelphia: J. P. Lippincott; 1970. p. 45

30. Thomas, L. Cellular and humoral aspects of the hypersensitive states. Lawrence, HS., editor. Hoeber; New York: 1959. p. 530

31. Walford RL, Hildemann WH. Amer J Pathol 1965;46:713. [PubMed: 5843415]

32. Wilson, WEC.; Kirkpatriek, CH. Experience in renal transplantation. Starzl, TE., editor. Saunders; Philadelphia: 1964. p. 239 


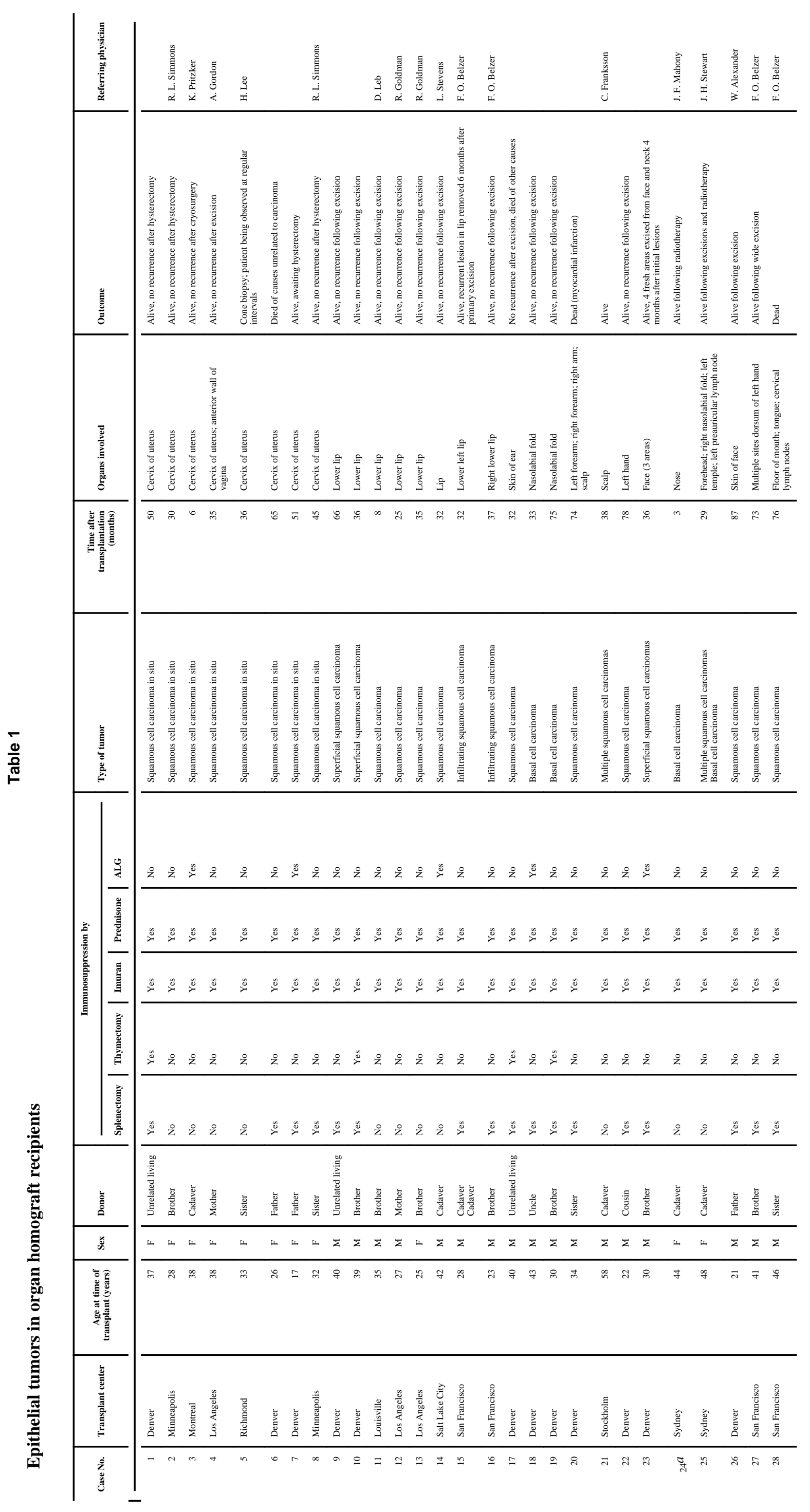




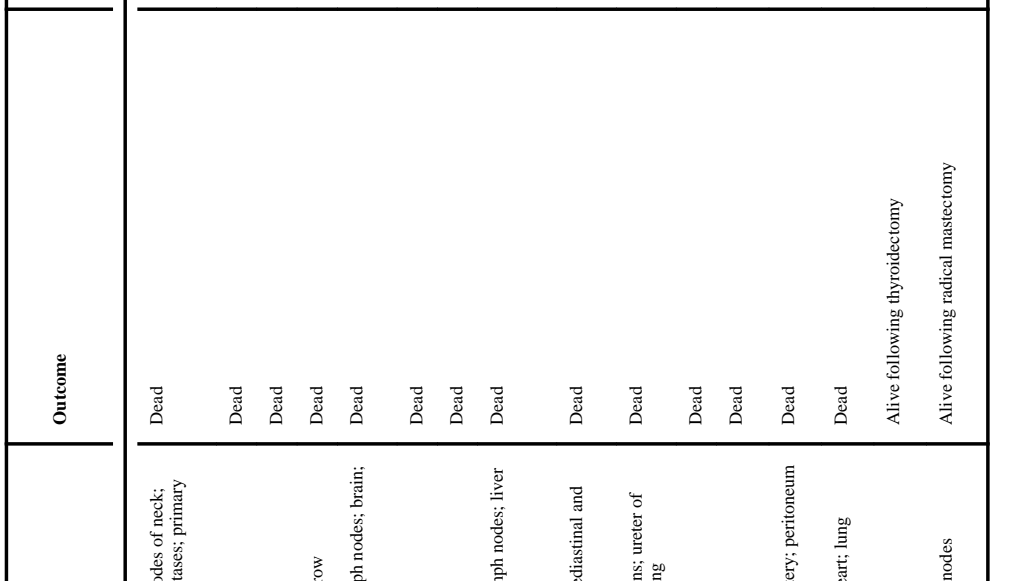

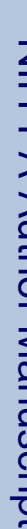

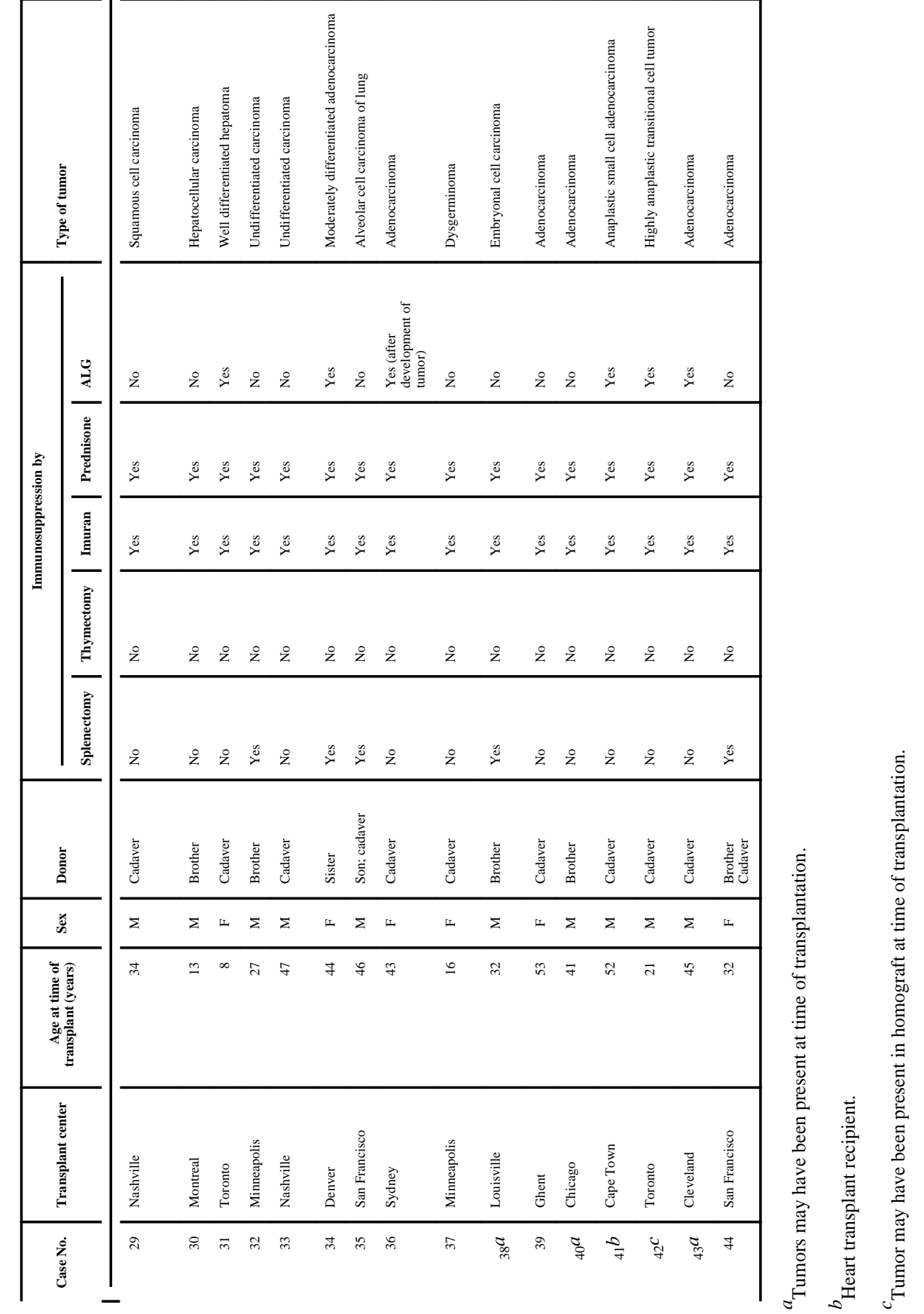




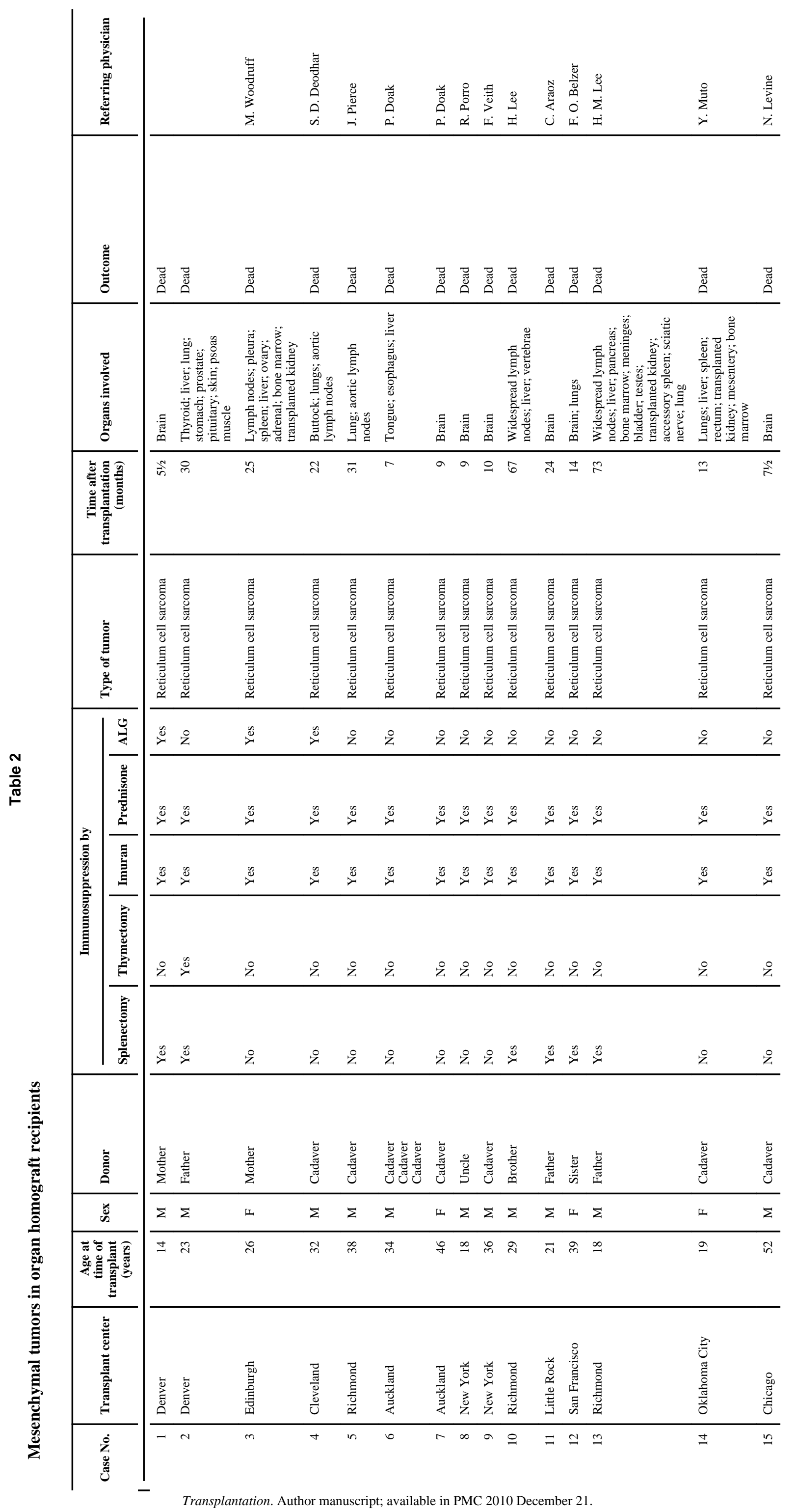




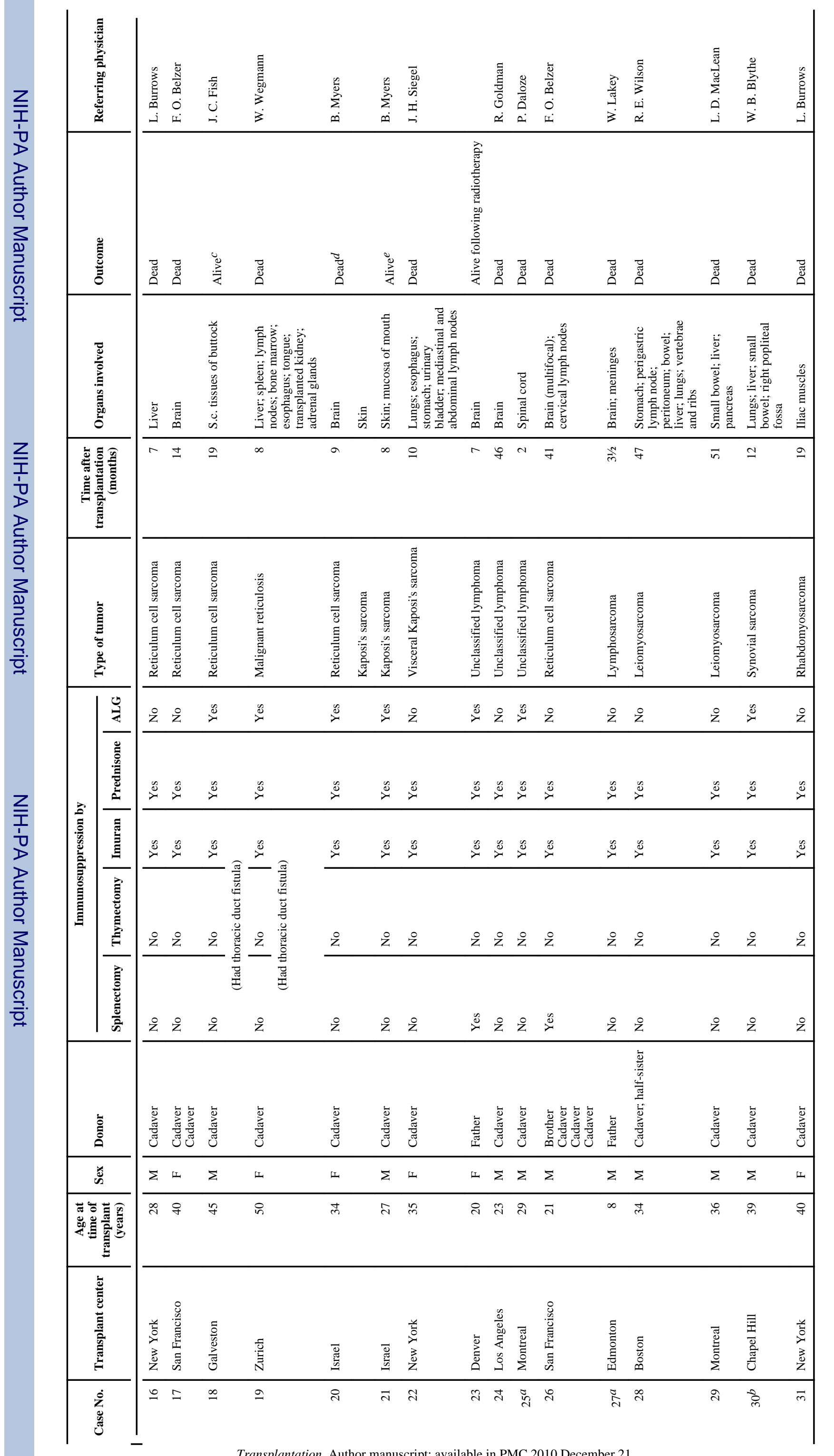

Transplantation. Author manuscript; available in PMC 2010 December 21. 


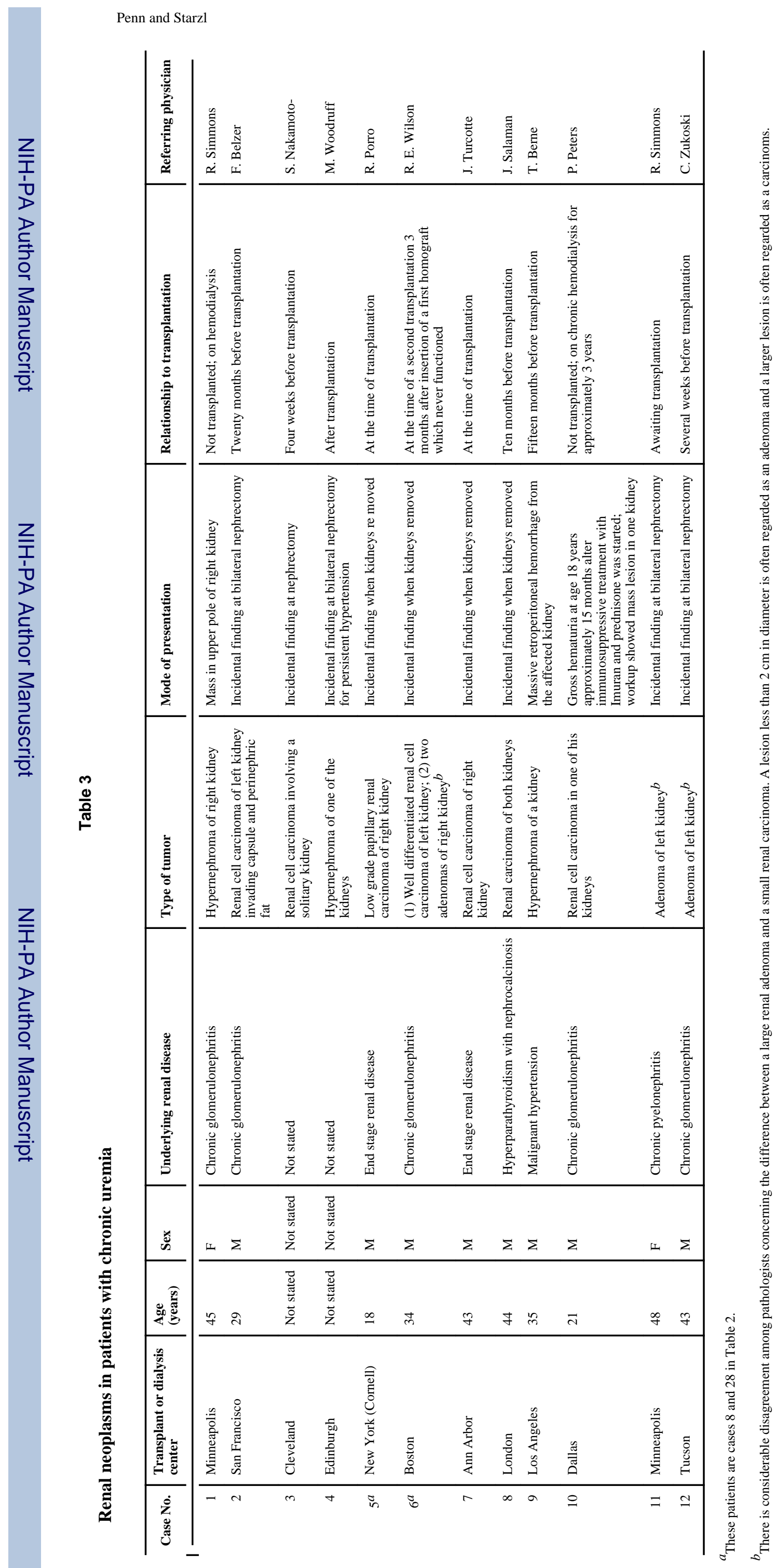

Page 12 